\title{
Chapter 7 \\ Reducing and Managing Uncertainty of Adaptation Recommendations to Increase user's Uptake
}

\author{
Margarita Ruiz-Ramos and Alfredo Rodríguez
}

\begin{abstract}
There are many challenges that adaptation science faces for an effective application of the results and recommendations found. Among the most important are the estimation, management and interpretation of uncertainty. In this article, we present our approach to managing uncertainty in agricultural projections using a combination of techniques to identify uncertainties, exclude unviable outcomes, consider possible futures probabilistically, and select the most robust projections for adaptation. Through an example of the adaptation of winter wheat in Spain, we show how this approach is effective in increasing the probability of avoiding maladaptation and improving the applicability and assimilation of scientific results by users.
\end{abstract}

Keywords Adaptation response surface, Ensemble Outcome Agreement, adaptation confidence

\section{Introduction}

According to the 2019 report of the World Economic Forum (WEF 2019), extreme weather events and failure on climate-change mitigation and adaptation are the two risks with the highest probability and the highest impact among the analysed in the report, with other issues such as water crises following them closely. These risks, when they turn into events, impose severe losses and damages to both private and public goods and activities, from small producers to insurance companies and administrations.

During the latest decades, a number of adaptation studies have been conducted. However, there are many challenges that adaptation science has to face for an effective application of the results and recommendations found. Among the most important

M. Ruiz-Ramos (凶)

CEIGRAM, Universidad Politécnica de Madrid, 28040 Madrid, Spain

e-mail: margarita.ruiz.ramos@upm.es

\author{
A. Rodríguez \\ Department of Economic Analysis and Finances, Universidad de Castilla-La Mancha, 45071 \\ Toledo, Spain \\ e-mail: alfredo.rodriguez@uclm.es \\ (C) The Author(s) 2022


are model errors, scarcity of observation records, lack of knowledge on the trade-offs with mitigation, political, social and behavioural barriers, and uncertainty estimation, management, and interpretation. This paper is focused on this last issue related to the adaptation of the agricultural sector to climate change.

Uncertainty of the adaptation assessments has many sources: The main one is the degree of success of mitigation, i.e., the scenario or RCP, which will determine the level of warming, seasonal patterns, and extremes with which adaptation will have to deal (Dosio and Fischer 2018). Another relevant source of uncertainty is model flaws and small observational records, especially for not mainstream measurements. This is valid for climate and impacts: for instance, in the climatology of extremes, or for crops other than the most common staple ones (wheat, maize, etc.), data and knowledge are poorer, as it is modelling performance consequently. Therefore there is always a degree of model error (that we can know when comparing to observations) and model uncertainty (e.g., in the case of future projections for which we cannot know in absence of a comparison reference). Efforts to reduce it are needed and approaches to do so are being developed and put in place, but also an improvement of its understanding and communication will help to handle the remaining uncertainty once such approaches have been applied. In this paper, we present our approach to handling the uncertainty of agricultural projections.

\section{Material and Methods}

\section{Climate Data}

Observed data for Spain were taken from a station of the Spanish Meteorological Agency (AEMET) located al Lleida (NE Spain) during the period 1980-2010. Variables at a daily scale were minimum and maximum temperatures (Tmin and Tmax, respectively), precipitation $(\mathrm{P})$, solar radiation or sun exposure (as a proxy for calculating solar radiation), humidity and wind speed. These data were used for crop model calibration and as baseline weather. $\mathrm{P}$ and temperature $(\mathrm{T})$ baseline values were perturbed, to conduct a sensitivity analysis, by using a "change factor" approach in combination with a seasonal pattern of the T and P changes (Fronzek et al. 2010).

As for climate change projections, RCMs simulation outputs from the EuroCORDEX domain (www.euro-cordex.net, last access: 7 July 2020) are used. These simulation outputs, with much higher resolution than GCMs, are particularly interesting for adaptation and mitigation studies. In this case, the $0.11^{\circ}$ resolution was selected. The simulations are forced by different GCMs and emission pathways (RCP2.6, RCP4.5 and RCP8.5, van Vuuren et al. (2011)). 


\section{Crop Data and Models}

Crop and soil data were required to calibrate crop models. Data were retrieved from published experiments from our research group or from other collaborating groups and literature. These data consisted of descriptions of the genetics of the crop and the cultivar in terms of phenology and growth potential. Also, information about the soil and common management and crop responses to favourable and stressed situations was required.

CERES-wheat crop model within DSSAT platform (Hoogenboom et al. 2019) was used for simulating wheat responses to climate change.

\section{Adaptation Modelling}

Adaptation consisted of a combination of changes of sowing dates, cultivar and water management. Baseline simulation referred to a winter cultivar describing those currently sown in the region, at the beginning of November, under rainfed conditions. Cultivar features modified were related to phenological characteristics, the vernalisation requirements and the length of the phenological phases. In the study region spring wheat can be sown in the same sowing dates as winter wheat; the decision on autumn rain. Shorter and longer growth cycles were simulated (+-20\% of season length), and the sowing date was advanced and delayed up to 45 days. Another option was supplementary irrigation, consisting of a single application of $40 \mathrm{~mm}$ at flowering. These adaptations were simulated separately and combined, by an ensemble of 17 members made up of 14 crop models and 17 modelling groups from MACSUR project (Ruiz-Ramos et al. 2018).

\section{Approaches for Uncertainty Reduction}

Several approaches have been applied depending on the estimate of the initial uncertainty. These are the bias adjustment (always applied), the ensemble modelling, the AOCK approach, the response surfaces and the Ensemble Outcome Agreement (EOA) index.

Ensemble modelling is a technique widely used in climate and also in agricultural projections, ideally, combining outputs from several climate models and crop models allow estimating the joint uncertainty from climate and crop modelling. Application of the AOCK approach, which consists in defining study-specific disqualifying criteria to be part of the ensemble, prevents for including inconsistencies that affect ensemble results (e.g., rainfed simulation projecting more yield than irrigated simulations in a dry environment). This approach is able to provide insights and improve ensemble effectiveness. Nevertheless, this has to be combined with other strategies 
to assure ensemble quality as the ensemble composition representing the spread of model projections and the use of medians instead of the mean as an average descriptor.

For situations of high uncertainty, the response surfaces approach is used. An Impact Response Surface (IRS) consists of a plotted surface that depicts the response of a studied variable (the so-called impact variable, e.g., crop yield) to combined changes in two explanatory variables (e.g., P and T). An Adaptation Response Surface (ARS) plots the difference between the impact variable responses (e.g., yield) with and without adaptation being considered, usually as a percentage of change. This metric is defined as the "adaptation value". It measures the effect of adaptation under a given combination of perturbations of $\mathrm{T}, \mathrm{P}$ and $\left[\mathrm{CO}_{2}\right]$ compared to the not adapted situation under the same perturbations. Another metric called "recovery value" refers to the difference between the yield response including an adaptation option and the baseline yield response (i.e., for an unperturbed simulation, $360 \mathrm{ppm}$ of $\left[\mathrm{CO}_{2}\right]$ and unadapted management). The "recovery value" measures the capacity of an adaptation option to maintain the yields of the baseline simulation under unperturbed conditions.

Finally, we develop an index of wide applicability for reducing the uncertainty, the so-called Ensemble Outcome Agreement (EOA) to assessing the confidence of the decisions taken regarding a threshold level, such as recommended adaptation options that are projected to provide positive adaptation values by the ensemble. Specifically, this index measures how the effect of changes in composition and size of a multi-model ensemble (MME) to evaluate the level of agreement between MME outcomes with respect to a given hypothesis (e.g., that adaptation measures result in positive crop responses). Definition of the index can be found in Rodríguez et al. (2019).

\section{Results and Discussion}

As application of the multi-model ensemble modelling, AOCK and IRS and ARS, recommendations for adaptation of wheat in Spain were produced as shown in Table 3 of Ruiz-Ramos et al. (2018). When EOA was applied to this dataset, Fig. 3 of Rodríguez et al. (2019) was obtained. The main added value of this further improvement was that by assigning an EOA value to every adaptation option, those that are otherwise promising in terms of adaptation response but show low confidence (i.e., low values of EOA) can be discarded, in favour of those with more confidence. Revisiting the recommendations of Ruiz-Ramos et al. (2018) in light of the EOA index generally resulted in an improvement by narrowing the range for which the adaptation options were effective.

While most of the winter-wheat based adaptations under rainfed conditions provided a very low value of EOA, at least 1 adaptation option, mainly based on spring wheat, was found with a high EOA value for every perturbation combination of $\mathrm{P}$ and $\mathrm{T}$. This supports the idea that adaptation would be possible under a wide range of future conditions. The number of effective adaptation options highly 
increased when supplementary irrigation was considered; in this case, some options provided positive results also for winter wheat.

As concerning sowing dates, EOA analysis supports the recommendations done Ruiz-Ramos et al. (2018) for adaptation, while for recovery the main difference was lower confidence reported by EOA for many cases. For adaptation response, recommendations for standard and longer cultivars were confirmed with very high or maximum confidence, while the confidence level was variable for high perturbations for rainfed spring wheat. For recovery response, the perturbation range for which spring wheat-based options were effective was smaller than previously estimated. For both adaptation and recovery response, the confidence level for shorter cultivars of both winter and spring wheat was lower than for the other cultivars, including some adaptation options previously recommended that now should be excluded. As a consequence, the revised recommendations would be to focus on early and standard sowing dates combined with standard and longer cultivars for meeting both adaptation and recovery targets under moderate perturbations with very high confidence, while there would be chances of achieving only adaptation benefit (impact reduction) with these options for severe perturbations. When the aim would be just to adapt, short spring cultivars could also be used with high confidence. The study demonstrates how omitting this analysis would result at least in a number of misleading recommendations under certain perturbations, resulting in maladaptation.

\section{Conclusions and Recommendations}

Adaptation of winter wheat in Spain relies on finding local optimal combinations of cultivars and management. In NE Spain, winter wheat under future conditions would benefit from switching to spring cultivars (i.e., no vernalisation requirements) with standard and longer cycle length, combined with early and standard sowing dates in autumn.

Techniques for managing uncertainty of agricultural projections or other projections depending on an uncertain future climate, such as EOA and others are as necessary as effective to increase the probability to avoid maladaptation and enhance the applicability and uptake of scientific results by users.

Acknowledgements Spanish National Institute for Agricultural and Food Research and Technology and Agencia Estatal de Investigación grant MACSUR02-APCIN2016-0005-00-00 and by the Comunidad de Madrid (Spain) and Structural Funds 2014-2020 (ERDF and ESF), project AGRISOST-CM S2018/BAA-4330. 


\section{References}

Dosio A, Fischer EM (2018) Will half a degree make a difference? Robust projections of indices of mean and extreme climate in Europe Under $1.5^{\circ} \mathrm{C}, 2^{\circ} \mathrm{C}$, and $3{ }^{\circ} \mathrm{C}$ global warming. Geophys Res Lett 45(2):935-944

Fronzek S, Carter TR, Raisanen J, Ruokolainen L, Luoto M (2010) Applying probabilistic projections of climate change with impact models: a case study for subarctic palsa mires in Fennoscandia. Clim Change 99(3-4):515-534

Hoogenboom G, Porter CH, Shelia V, Boote KJ, Singh U, White JW, Hunt LA, Ogoshi R, Lizaso JI, Koo J, Asseng S, Singels A, Moreno LP, Jones JW (2019) Decision support system for agrotechnology transfer (DSSAT) version 4.7.5. DSSAT Foundation, Gainesville, Florida, USA. https://DSSAT.net

Piani C, Haerter JO, Coppola E (2010) Statistical bias correction for daily precipitation in regional climate models over Europe. Theoret Appl Climatol 99(1-2):187-192

Richardson EA, Seeley SD, Walker DR (1974) A model for estimating the completion of rest for "Redhaven" and "Elberta" peach trees. HortScience 1:331-332

Rodríguez A et al (2019) Implications of crop model ensemble size and composition for estimates of adaptation effects and agreement of recommendations. Agric Meteorol 264:351-362

Ruiz-Ramos $\mathrm{M}$ et al (2018) Adaptation response surfaces for managing wheat under perturbed climate and CO2 in a Mediterranean environment. Agric Syst 159:260-274

Ruiz-Ramos $\mathrm{M}$ et al (2016) Comparing correction methods of RCM outputs for improving crop impact projections in the Iberian Peninsula for 21st century. Clim Change 134(1):283-297

Shaltout AD, Unrath CR (1983) Rest completion prediction model for "Starkrimson Delicious" apples. J Amer Soc Hort Sci 108(6):957-961

van Vuuren DP et al (2011) The representative concentration pathways: an overview. Clim Change 109:5-31

WEF (2019) The GlobalCompetitiveness Report. World Economic Forum, Geneva, p 666

Open Access This chapter is licensed under the terms of the Creative Commons Attribution 4.0 International License (http://creativecommons.org/licenses/by/4.0/), which permits use, sharing, adaptation, distribution and reproduction in any medium or format, as long as you give appropriate credit to the original author(s) and the source, provide a link to the Creative Commons license and indicate if changes were made.

The images or other third party material in this chapter are included in the chapter's Creative Commons license, unless indicated otherwise in a credit line to the material. If material is not included in the chapter's Creative Commons license and your intended use is not permitted by statutory regulation or exceeds the permitted use, you will need to obtain permission directly from the copyright holder.

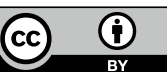

